\title{
(2) OPEN ACCESS \\ Health of mothers of children with a life-limiting condition: a comparative cohort study
}

\author{
Lorna K Fraser (D , , ${ }^{1}$ Fliss EM Murtagh, ${ }^{2}$ Jan Aldridge, ${ }^{3}$ Trevor Sheldon, ${ }^{4}$ \\ Simon Gilbody, ${ }^{1}$ Catherine Hewitt ${ }^{1}$
}

\begin{abstract}
- Additional material is published online only. To view, please visit the journal online (http://dx.doi.org/10.1136/ archdischild-2020-320655).

${ }^{1}$ Health Sciences, University of York, York, UK

${ }^{2}$ Hull York Medical School, University of Hull, Hull, UK ${ }^{3}$ Clinical Psychology, Leeds Teaching Hospitals NHS Trust, Leeds, UK

${ }^{4}$ School of Medicine, Queen Mary University of London, London, UK
\end{abstract}

\section{Correspondence to}

Dr Lorna K Fraser, Health

Sciences, University of York, York Y010 5DD, UK;

lorna.fraser@york.ac.uk

Received 7 September 2020 Revised 17 January 2021

Accepted 31 January 2021 Published Online First 2 March 2021

\section{Check for updates}

(c) Author(s) (or their employer(s)) 2021. Re-use permitted under CC BY. Published by BMJ.

To cite: Fraser LK, Murtagh FEM, Aldridge J, et al. Arch Dis Child 2021:106:987-993.

\begin{abstract}
Objective This study aimed to quantify the incidence rates of common mental and physical health conditions in mothers of children with a life-limiting condition.

Methods Comparative national longitudinal cohort study using linked primary and secondary care data from the Clinical Practice Research Datalink in England. Maternal-child dyads were identified in these data. Maternal physical and mental health outcomes were identified in the primary and secondary care datasets using previously developed diagnostic coding frameworks. Incidence rates of the outcomes were modelled using Poisson regression, adjusting for deprivation, ethnicity and age and accounting for time at risk.
\end{abstract}

Results A total of 35683 mothers; 8950 had a child with a life-limiting condition, 8868 had a child with a chronic condition and 17865 had a child with no longterm condition.

The adjusted incidence rates of all of the physical and mental health conditions were significantly higher in the mothers of children with a life-limiting condition when compared with those mothers with a child with no longterm condition (eg, depression: incidence rate ratio (IRR) $1.21,95 \% \mathrm{Cl} 1.13$ to 1.30 ; cardiovascular disease: IRR $1.73,95 \% \mathrm{Cl} 1.27$ to 2.36 ; death in mothers: IRR 1.59, $95 \% \mathrm{Cl} 1.16$ to 2.18$)$.

Conclusion This study clearly demonstrates the higher incidence rates of common and serious physical and mental health problems and death in mothers of children with a life-limiting condition. Further research is required to understand how best to support these mothers, but healthcare providers should consider how they can target this population to provide preventative and treatment services.

There are more than 86000 children living in England with conditions ${ }^{1}$ which will either ultimately shorten their life (eg, Leigh's disease) or conditions for which treatment may be available but may fail (eg, cancer). ${ }^{2}$ The defining feature of children with a life-limiting or life-threatening condition is that these children are at risk of premature death, and dying in childhood or early adulthood may be expected. Now, these children are living longer in part due to the more aggressive management of complications ${ }^{3}$ and the increasing use of medical technologies (eg, home ventilation). ${ }^{4}$

It is often expected that parents of these children, predominately the mother, ${ }^{5}$ become healthcare providers as well as parents, 24 hours a day 7 days a week. The health of these mothers is important,

\section{What is already known on this topic?}

- There are growing numbers of children with life-limiting conditions in which the mothers provide healthcare 24 hours, 7 days a week.

- There is evidence of an increased risk of mortality among mothers whose infant has died or has a significant congenital anomaly.

- Most healthcare services focus on individual patients and not the whole family, thus ignoring the needs of parents.

What this study adds?

- Mothers of children with a life-limiting condition have significantly higher incidence of depression, anxiety and serious mental illness than other mothers.

- They also have significantly higher incidence of cardiovascular disease, hypertension and mortality.

- Much of this morbidity may be preventable.

both in terms of caring for their child but also in their own right to health and well-being. Most healthcare services focus on individual patients and not the whole family, therefore ignoring the needs of parents.

The lack of studies quantifying the mental health of mothers of children with a life-limiting condition has been highlighted by the National Institute for Health and Care Excellence. ${ }^{6}$ Although studies show that mothers of children with special needs ${ }^{7}$ or specific disabilities ${ }^{89}$ have shown higher levels of parental distress or emotional problems than parents of healthy children, these studies do not address the specific needs of those with life-limiting conditions or the added burden that their parents face, knowing their child is likely to die.

There is evidence of an increased risk of mortality among mothers whose infant has died or has a significant congenital anomaly. ${ }^{1011}$ However, there is little evidence about the physical health of mothers of children with life-limiting conditions. Two cross-sectional studies in mothers of children with disabilities found higher prevalence of self-reported physical conditions compared with mothers of healthy children (eg, back pain, 35.2\% vs $26.7 \%$, and hypertension, $24.7 \%$ vs $19.1 \%$ ). ${ }^{912}$

Quantifying and understanding the physical and mental health of these mothers is vital before any 
effective interventions can be designed, targeted or tested. ${ }^{6}$ Therefore, this study aims to quantify the incidence of commonly occurring mental and physical health conditions in mothers of children with a life-limiting condition using a nationally representative longitudinal healthcare dataset.

\section{METHODS}

This observational comparative cohort study was conducted in accordance with a protocol and reported according to the Strengthening the Reporting of Observational Studies in Epidemiology-RECORD guidelines. ${ }^{13}$

\section{Data sources}

The study used an anonymised extract of data from the Clinical Practice Research Datalink (CPRD) GOLD dataset, which contains longitudinal primary care records from a representative sample of general practitioner (GP) practices across the UK (covering approximately $8.5 \%$ of the UK population) ${ }^{14}$ linked to records from secondary care data (Hospital Episodes Statistics (HES) and the Mental Health Minimum Dataset (MHMDS)) $)^{15} 16$ and Office for National Statistics (ONS) death certificate data. The datasets were linked using deterministic methods by CPRD using NHS number, sex, date of birth and postcode, ${ }^{16}$ and mothers were linked to their children using the CPRD motherbaby link algorithm, which is based on pregnancy records. ${ }^{15}$

The CPRD GOLD dataset ${ }^{14}$ contains information on consultations, prescriptions and referrals. HES contains information about clinical diagnosis and procedures, and patient information including age, sex and ethnicity, for all inpatient stays. ${ }^{17}$ MHMDS contains information on individuals who have received specialist secondary mental healthcare, including outpatient, inpatient and community care. ${ }^{18}$

\section{Cohort identification}

The cohort was identified by the CPRD team via the disease group of the children (see online supplemental material). The identification of life limiting and chronic disease in the children was undertaken using previously developed Read code frameworks (primary care) or International Classification of Diseases code frameworks (secondary care) for life-limiting ${ }^{19} 20$ and chronic conditions ${ }^{21}$ in children.

The index children (life-limiting conditions) were included if they were eligible for HES linkage (ie, resident in England) and where the mother had at least 1 year of registration in the CPRD dataset, between 1 April 2007 and 31 December 2017. These eligible children were then matched to children with chronic conditions $(1: 1)$ or no long-term conditions $(1: 2)$ on year of birth, sex and geographical region. All primary and secondary care for the child-mother dyads were extracted.

\section{Outcomes}

The health outcomes for mothers were identified by the authors using Read coded data in the CPRD GOLD dataset (clinical interaction data including symptoms, diagnoses, referrals and prescriptions) or International Classification of Diseases, 10th Revision, diagnostic codes in the secondary healthcare data. These outcomes are common health conditions seen in primary care and could be plausibly linked to the physical or psychological pressure of having a child with a chronic or life-limiting condition. The code lists for each outcome were identified using previously published studies (online supplemental material).
Mental health outcomes

- Anxiety. $^{22}$

- Depression. ${ }^{22}$

- Serious mental illness (schizophrenia and bipolar disorder). ${ }^{23}$

- Referral to secondary mental health services (present in the MHMDS).

Physical health outcomes

- Back pain ${ }^{24}$

- Obesity 2526

- Hypertension ${ }^{24}$

- Cardiovascular disease (CVD). ${ }^{22}$

- Type 2 diabetes mellitus ${ }^{25} 26$

- Death, via the linkage to the ONS death registration data.

Time at risk was calculated separately for each outcome of interest and from the point of child's diagnosis to the recording of the outcome of interest or end date of the mother. Incidence rates were calculated per person years at risk for each outcome.

Mothers who had a diagnosis of an outcome of interest prior to the record of diagnoses in their child were excluded from the analyses only for that outcome-this enabled us to exclude diagnoses in the mothers that occurred prior to their child's diagnosis.

\section{Other variables of interest}

The age of the mother was calculated as the age at their entry to this study.

The deprivation category, a measure of socioeconomic status (split into five groups using the Index of Multiple Deprivation 2010), ${ }^{27}$ was provided as linked data based on the most recent known address of the individual.

The ethnic group (black African, black Caribbean, black Other, Chinese, Bangladeshi, Indian, Pakistani, other Asian, white, mixed or other ${ }^{28}$ ) was recorded in the linked HES data, where an individual had more than one ethnic group, provided it was set by CPRD to the most commonly recorded value, excluding unknown. Due to the small number in some of these ethnic groups, categories were collapsed into six groups; white, South Asian, black, Chinese, mixed and other.

Smoking status was using the Read code list available for current smoking status. $^{22}$

\section{Statistical methods}

Crude incidence rates of the physical and mental health conditions were calculated in each group of mothers by dividing the number of cases in each group by the person-time at risk in each group.

Multivariable Poisson models were built for each outcome of interest and included maternal age, ethnicity, deprivation status, number of GP consultations and the matching variables (child birth year, child sex and region) to compare the incidence rates between the groups of mothers using incidence rate ratios (IRRs) and accounting for time at risk. Confounding variables were retained if they improved the model fit (via Bayesian Information Criterion).

Analyses were undertaken using STATA V.15. ${ }^{29}$

\section{Patient and public involvement}

The views of parents and carers of children with a life-limiting condition informed the development of this study, including refining the research question.

\section{RESULTS}

The cohort for analyses contained 35683 mothers, of whom 8950 had a child with a life-limiting condition; 8868 had a child 
Table 1 Participant characteristics

\begin{tabular}{|c|c|c|c|c|c|c|c|c|}
\hline & \multicolumn{2}{|c|}{$\begin{array}{l}\text { Child has a life-limiting } \\
\text { condition }\end{array}$} & \multicolumn{2}{|c|}{ Child has a chronic condition } & \multicolumn{2}{|c|}{$\begin{array}{l}\text { Child has no long-term } \\
\text { condition }\end{array}$} & \multicolumn{2}{|l|}{ Total } \\
\hline & $\mathrm{n}$ & $\%$ & & $\%$ & & $\%$ & & $\%$ \\
\hline Total mothers & 8950 & & 8868 & & 17865 & & 35683 & \\
\hline Mothers' mean age (years) (SD) & $34.0(7.7)$ & & $33.8(7.3)$ & & $34.1(7.2)$ & & $34.0(7.4)$ & \\
\hline Min-max & $15-64$ & & $15-62$ & & $15-62$ & & $15-64$ & \\
\hline \multicolumn{9}{|l|}{ Deprivation category } \\
\hline 1 (least deprived) & 1853 & 20.7 & 2037 & 23.0 & 4596 & 25.7 & 8486 & 23.8 \\
\hline 2 & 1826 & 20.4 & 1749 & 19.7 & 3597 & 20.1 & 7172 & 20.1 \\
\hline 3 & 1732 & 19.4 & 1685 & 19.0 & 3365 & 18.8 & 6782 & 19.0 \\
\hline 4 & 1827 & 20.4 & 1753 & 19.8 & 3319 & 18.6 & 6899 & 19.3 \\
\hline 5 (most deprived) & 1706 & 19.1 & 1642 & 18.5 & 2979 & 16.7 & 6327 & 17.7 \\
\hline Missing & 6 & 0.1 & 2 & 0.0 & 9 & 0.1 & 17 & 0.0 \\
\hline \multicolumn{9}{|l|}{ Ethnic group } \\
\hline White & 7272 & 81.3 & 7341 & 82.8 & 14578 & 81.6 & 29191 & 81.8 \\
\hline South Asian & 584 & 6.5 & 520 & 5.9 & 940 & 5.3 & 2044 & 5.7 \\
\hline Black & 323 & 3.6 & 310 & 3.5 & 524 & 2.9 & 1157 & 3.2 \\
\hline Chinese & 42 & 0.5 & 29 & 0.3 & 94 & 0.5 & 165 & 0.5 \\
\hline Mixed & 90 & 1.0 & 80 & 0.9 & 165 & 0.9 & 335 & 0.9 \\
\hline Other & 156 & 1.7 & 133 & 1.5 & 310 & 1.7 & 599 & 1.7 \\
\hline Unknown & 483 & 5.4 & 455 & 5.1 & 1254 & 7.0 & 2192 & 6.1 \\
\hline \multicolumn{9}{|c|}{ Number of GP consultations in analyses period } \\
\hline Median & 20 & & 29 & & 22 & & 23 & \\
\hline Q1, Q3 & 9, 39 & & 15,51 & & 11,39 & & 11,42 & \\
\hline Min-max & $1-391$ & & $1-451$ & & $1-451$ & & $1-451$ & \\
\hline \multicolumn{9}{|l|}{ Region } \\
\hline North East & 223 & 2.5 & 220 & 2.5 & 439 & 2.5 & 882 & 2.5 \\
\hline North West & 1446 & 16.2 & 1439 & 16.2 & 2888 & 16.2 & 5773 & 16.2 \\
\hline Yorkshire and Humber & 257 & 2.9 & 248 & 2.8 & 511 & 2.9 & 1016 & 2.8 \\
\hline East Midlands & 249 & 2.8 & 240 & 2.7 & 495 & 2.8 & 984 & 2.8 \\
\hline West Midlands & 971 & 10.8 & 968 & 10.9 & 1940 & 10.9 & 3879 & 12.8 \\
\hline East of England & 1145 & 12.8 & 1141 & 12.9 & 2288 & 12.8 & 4574 & 12.8 \\
\hline South West & 1157 & 12.9 & 1140 & 12.9 & 2311 & 12.9 & 4608 & 12.9 \\
\hline South Central & 1118 & 12.5 & 1104 & 12.4 & 2229 & 12.5 & 4451 & 12.5 \\
\hline London & 1317 & 14.7 & 1308 & 14.7 & 2634 & 14.7 & 5259 & 14.7 \\
\hline South East Coast & 1067 & 11.9 & 1060 & 12.0 & 2130 & 11.9 & 4257 & 11.9 \\
\hline \multicolumn{9}{|l|}{ Length of follow-up (years) } \\
\hline Mean (SD) & $6.7(3.4)$ & & $7.8(3.1)$ & & $7.5(3.2)$ & & $7.3(3.2)$ & \\
\hline Min-max & $1.1-12.1$ & & $1.0-12.1$ & & $1.0-12.1$ & & $1.0-12.1$ & \\
\hline Current smoker & 2098 & 23.4 & 2228 & 25.1 & 4133 & 23.1 & 8459 & 23.7 \\
\hline
\end{tabular}

GP, general practitioner.

with a chronic condition; and 17865 had a child with no longterm condition (table 1 ).

There were few missing data apart from ethnic group (6\% unknown ethnicity). Unknown ethnic group was retained as a category for analyses (table 1).

Mothers of children with a life-limiting condition on average visited the GP less frequently (median $=20$ ) than mothers of children with a chronic condition (median $=29$, table 1 ).

The numbers of mothers removed from each incidence analyses as they were diagnosed prior to their child's diagnoses are as follows:

- Depression 10558.

- Anxiety 5862 .

- Serious mental illness 165.

- Referral to secondary mental health services 820 .

- Hypertension 1308.

- CVD 76.
- Type 2 diabetes 332 .

- Back pain 12193.

The crude incidence rates of depression, anxiety, serious mental illness and referral to secondary mental health services are significantly higher in the mothers of children with a lifelimiting or chronic condition when compared with mothers whose children have no long-term condition (table 2).

The crude incidence rates of obesity, hypertension, type 2 diabetes and back pain are significantly higher in the mothers of children with a life-limiting or chronic condition when compared with mothers whose children have no long-term condition; for example, for depression, crude incidence rates were 341 (95\% CI 322 to 361), 340 (95\% CI 322 to 359) and 268 (95\% CI 257 to 259) per 10000 person years, respectively. The crude incidence rates of CVD are significantly higher in mothers of children with a life-limiting condition (13.4 per 10000 person years, $95 \%$ CI 10.8 to 16.7 ), but not in those of a child with a 
Table 2 Crude incidence rates of physical and mental health conditions in mothers by diagnostic group of the child

\begin{tabular}{|c|c|c|c|c|c|c|c|c|c|}
\hline & \multicolumn{3}{|c|}{ Child has a life-limiting condition } & \multicolumn{3}{|c|}{ Child has a chronic condition } & \multicolumn{3}{|c|}{ Child has no long-term condition } \\
\hline & $\begin{array}{l}\text { Incident } \\
\text { cases (n) }\end{array}$ & $\begin{array}{l}\text { Incidence } \\
\text { per } 10000 \\
\text { person years }\end{array}$ & $95 \%$ Cls & $\begin{array}{l}\text { Incident } \\
\text { cases (n) }\end{array}$ & $\begin{array}{l}\text { Incidence } \\
\text { per } 10000 \\
\text { person years }\end{array}$ & $95 \% \mathrm{Cls}$ & $\begin{array}{l}\text { Incident } \\
\text { cases (n) }\end{array}$ & $\begin{array}{l}\text { Incidence } \\
\text { per } 10000 \\
\text { person years }\end{array}$ & $95 \% \mathrm{Cls}$ \\
\hline \multicolumn{10}{|l|}{ Mental health outcomes } \\
\hline Depression & 1196 & 341 & 322 to 361 & 1343 & 340 & 322 to 359 & 2350 & 268 & 257 to 279 \\
\hline Anxiety & 917 & 201 & 188 to 214 & 1104 & 212 & 200 to 225 & 1816 & 168 & 160 to 176 \\
\hline Serious mental illness & 60 & 10.1 & 7.8 to 13 & 55 & 8 & 6.2 to 10.4 & 55 & 5.5 & 4.3 to 6.8 \\
\hline MHMDS & 712 & 46.2 & 40.7 to 52.3 & 647 & 37.5 & 33 to 42.6 & 1022 & 26.8 & 24.1 to 29.8 \\
\hline \multicolumn{10}{|l|}{ Physical health outcomes } \\
\hline Obesity & 693 & 128 & 119 to 138 & 711 & 115 & 107 to 124 & 1126 & 91.1 & 85.9 to 96.6 \\
\hline Cardiovascular disease & 80 & 13.4 & 10.8 to 16.7 & 59 & 8.6 & 6.7 to 11.1 & 86 & 6.4 & 5.2 to 7.9 \\
\hline Hypertension & 470 & 84.3 & 77 to 92.2 & 512 & 79.3 & 72.8 to 86.6 & 725 & 57.1 & 53.1 to 61.4 \\
\hline Type 2 diabetes & 168 & 28.7 & 24.7 to 33.4 & 180 & 26.6 & 23 to 30.7 & 271 & 20.3 & 18.1 to 22.1 \\
\hline Back pain & 1316 & 402 & 381 to 424 & 1641 & 471 & 449 to 495 & 2835 & 364 & 351 to 377 \\
\hline Death & 68 & 11.4 & 9.0 to 14.4 & 41 & 6.0 & 4.4 to 8.1 & 91 & 6.8 & 5.5 to 8.3 \\
\hline
\end{tabular}

IRR, incidence rate ratio; MHMDS, Mental Health Minimum Dataset.

chronic condition (8.6 per 10000 person years, 95\% CI 6.7 to 11.1) when compared with mothers whose children have no long-term condition (6.4 per 10000 person years, 95\% CI 5.2 to 7.9$)$.

The crude rate of death (11.4 per 10000 person years, 95\% CI 9.0 to 14.4 ) was significantly higher in mothers of children with a life-limiting condition, but not in those of a child with a chronic condition (6.0 per 10000 person years, 95\% CI 4.4 to 8.1) when compared with mothers whose children have no long-term condition (6.8 per 10000 person years, 95\% CI 5.5 to 8.3 ; table 2 ). The univariate models are available in the online supplemental material.

There is significantly higher incidence of all mental health outcomes in mothers of children with a life-limiting condition when compared with mothers whose children have no long-term condition (eg, depression IRR 1.21, 95\% CI 1.13 to 1.30 ) in the adjusted analyses (figure 1 and table 3 ). For mothers whose child has a chronic condition the incidence of depression, anxiety and referral to secondary mental health services are significantly higher than for mothers whose children have no long-term condition, but their incidence of serious mental illness was not significantly different (IRR $1.17,95 \%$ CI 0.82 to 1.67 ).

For all the physical health outcomes in mothers (figure 1 and table 4), the incidence rates are significantly higher in mothers of children with a life-limiting condition when compared with mothers whose children have no long-term condition (eg, CVD IRR 1.73 , 95\% CI 1.27 to 2.36 ). For mothers whose child has a chronic condition, the incidence of obesity, hypertension and back pain are significantly higher than for mothers whose children have no long-term condition, but their incidence of type 2 diabetes (IRR $1.09,95 \%$ CI 0.90 to 1.32 ) and CVD (IRR 1.06, $95 \%$ CI 0.76 to 1.49 ) was not significantly different.

The adjusted incidence rates of death in mothers of children with a life-limiting condition was higher (IRR 1.59, 95\% CI 1.16 to 2.18) than those in mothers whose child had no long-term condition (figure 1).

\section{DISCUSSION}

This population-based study has shown that the incidence rates of both common mental and physical health conditions are

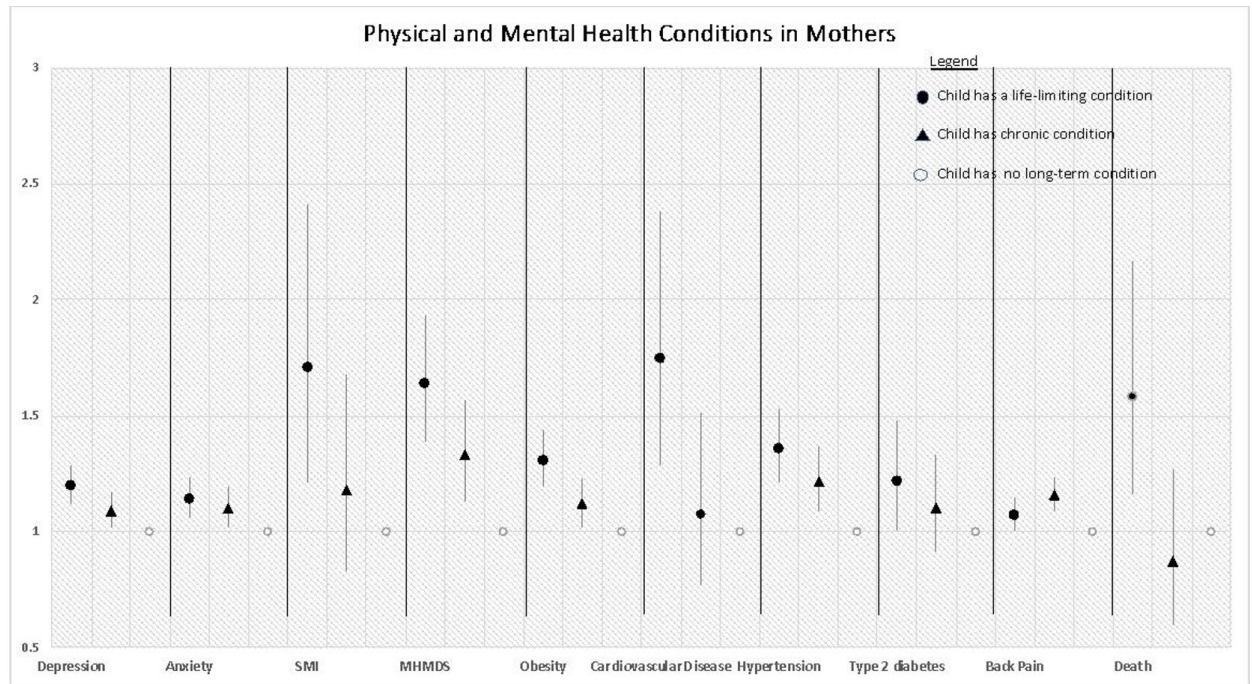

Figure 1 Physical and mental health conditions in mothers; adjusted incidence rate ratios (models adjusted for age of mother, index of multiple deprivation, ethnic group, number of general practitioner consults; smoking status was also included in the models for cardiovascular disease and hypertension). 
Table 3 Multivariable models for maternal mental health outcomes

\begin{tabular}{|c|c|c|c|c|c|c|c|c|}
\hline & Anxiety & $n=29392$ & Depression & $n=24754$ & $\begin{array}{l}\text { Serious mental } \\
\text { illness }\end{array}$ & $n=35036$ & $\begin{array}{l}\text { Referral to secondary } \\
\text { mental health services }\end{array}$ & $\mathrm{n}=32842$ \\
\hline & IRR & $95 \% \mathrm{Cl}$ & IRR & $95 \% \mathrm{Cl}$ & IRR & $95 \% \mathrm{Cl}$ & IRR & $95 \% \mathrm{Cl}$ \\
\hline Child has no long-term condition & REF & & REF & & REF & & REF & \\
\hline Child has a life-limiting condition & 1.16 & 1.07 to 1.25 & 1.21 & 1.13 to 1.30 & 1.66 & 1.17 to 2.34 & 1.61 & 1.37 to 1.90 \\
\hline Child has a chronic condition & 1.11 & 1.03 to 1.19 & 1.09 & 1.02 to 1.17 & 1.17 & 0.82 to 1.67 & 1.17 & 0.98 to 1.38 \\
\hline Mothers' age & 0.97 & 0.97 to 0.98 & 0.97 & 0.96 to 0.97 & 0.94 & 0.92 to 0.96 & 0.95 & 0.94 to 0.96 \\
\hline \multicolumn{9}{|l|}{ Deprivation category } \\
\hline 1 (least deprived) & REF & & REF & & REF & & REF & \\
\hline 2 & 0.99 & 0.89 to 1.10 & 1.06 & 0.97 to 1.15 & 1.28 & 0.76 to 2.15 & 1.65 & 1.29 to 2.14 \\
\hline 3 & 1.13 & 1.02 to 1.25 & 1.12 & 1.03 to 1.23 & 1.25 & 0.74 to 2.11 & 1.88 & 1.46 to 2.42 \\
\hline 4 & 1.15 & 1.04 to 1.27 & 1.23 & 1.13 to 1.35 & 1.69 & 1.03 to 2.76 & 2.00 & 1.56 to 2.57 \\
\hline 5 (most deprived) & 1.16 & 1.04 to 1.29 & 1.37 & 1.24 to 1.50 & 1.68 & 1.00 to 2.81 & 2.09 & 1.61 to 2.70 \\
\hline \multicolumn{9}{|l|}{ Ethnic group } \\
\hline White & REF & & REF & & REF & & REF & \\
\hline South Asian & 0.52 & 0.44 to 0.62 & 0.44 & 0.38 to 0.51 & 0.32 & 0.12 to 0.86 & 0.62 & 0.43 to 0.89 \\
\hline Black & 0.43 & 0.32 to 0.56 & 0.54 & 0.45 to 0.66 & 0.78 & 0.28 to 2.18 & 0.51 & 0.30 to 0.86 \\
\hline Chinese & 0.76 & 0.44 to 1.30 & 0.35 & 0.19 to 0.65 & 0.00 & 0 & 0.00 & 0.00 \\
\hline Mixed & 0.96 & 0.69 to 1.33 & 0.91 & 0.68 to 1.22 & 1.94 & 0.61 to 6.14 & 0.62 & 0.26 to 1.49 \\
\hline Other & 0.66 & 0.48 to 0.89 & 0.57 & 0.44 to 0.74 & 1.05 & 0.33 to 3.33 & 0.94 & 0.53 to 1.68 \\
\hline Missing & 0.63 & 0.53 to 0.76 & 0.70 & 0.60 to 0.81 & 0.23 & 0.06 to 0.93 & 0.51 & 0.32 to 0.81 \\
\hline Number of GP consultations & 1.01 & 1.01 to 1.01 & 1.01 & 1.01 to 1.01 & 1.01 & 1.01 to 1.01 & 1.01 & 1.01 to 1.01 \\
\hline \multicolumn{9}{|l|}{ Region } \\
\hline North East & 2.11 & 1.73 to 2.57 & 1.61 & 1.34 to 1.94 & 0.91 & 0.30 to 2.73 & 0.73 & 0.44 to 1.24 \\
\hline North West & 1.43 & 1.27 to 1.62 & 1.29 & 1.16 to 1.43 & 1.56 & 0.89 to 2.72 & 0.53 & 0.39 to 0.72 \\
\hline Yorkshire and Humber & 1.04 & 0.83 to 1.30 & 0.93 & 1.16 to 1.43 & 0.21 & 0.03 to 1.58 & 1.05 & 0.67 to 1.65 \\
\hline East Midlands & 2.09 & 1.68 to 2.61 & 2.20 & 1.81 to 2.68 & 3.37 & 1.45 to 7.87 & 1.62 & 1.00 to 2.64 \\
\hline West Midlands & 1.24 & 1.08 to 1.42 & 1.19 & 1.06 to 1.33 & 1.02 & 0.54 to 1.91 & 1.04 & 0.79 to 1.37 \\
\hline East of England & 1.05 & 0.91 to 1.20 & 1.00 & 0.89 to 1.13 & 1.04 & 0.54 to 2.01 & 0.61 & 0.44 to 0.84 \\
\hline South West & 1.37 & 1.20 to 1.55 & 1.19 & 1.07 to 1.34 & 0.80 & 0.42 to 1.53 & 1.87 & 1.47 to 2.38 \\
\hline South Central & 1.13 & 0.99 to 1.29 & 1.23 & 1.09 to 1.38 & 1.12 & 0.59 to 2.12 & 0.29 & 0.19 to 0.44 \\
\hline London & REF & & & & & & & \\
\hline South East Coast & 1.03 & 0.90 to 1.18 & 1.07 & 0.96 to 1.20 & 1.09 & 0.58 to 2.03 & 1.16 & 0.89 to 1.51 \\
\hline \multicolumn{9}{|l|}{ Child sex } \\
\hline Male & REF & & & & & & & \\
\hline Female & 0.97 & 0.91 to 1.04 & 1.02 & 0.96 to 1.08 & 0.94 & 0.70 to 1.26 & 1.05 & 0.91 to 1.21 \\
\hline Baby birth year & 1.01 & 1.01 to 1.02 & 1.03 & 1.02 to 1.03 & 0.96 & 0.93 to 0.99 & 0.99 & 0.98 to 1.01 \\
\hline
\end{tabular}

GP, general practitioner; IRR, incidence rate ratio; REF, reference.

higher in mothers of children with a life-limiting condition when compared with mothers whose child has no long-term health condition. However, these mothers visited their GP practices less frequently. The risk of death was also more than 50\% higher in this population of mothers. Much of this excess morbidity may be preventable through proactive healthcare incorporating both primary and secondary prevention initiatives.

Previous studies assessing the health outcomes of mothers have either been in specific groups of children with intellectual or broader disabilities and have focused on the mental health outcomes. ${ }^{830-34}$ The current findings are consistent with a recent meta-analysis that highlighted the increased risk of depressive symptoms and poorer general health of mothers of children with developmental disabilities ${ }^{34}$ and with previous studies of the health of mothers with children with physical disabilities. ${ }^{30} 35$

Many published studies have not differentiated between mothers of children with life-limiting or other chronic conditions. $^{34} 36$ This study differentiates between these groups to address the additional layer of complexity within these mother's lives in that they are aware that their child will die prematurely ${ }^{37}$ and also enables comparison between the groups to assess the dose-response element of the relationship with the outcomes. A recent cross-sectional study of parents of children being cared for by a palliative care service estimated that nearly half of these parents showed signs of clinically elevated stress, depression or anxiety. $^{38}$

The finding of higher risk of death in this population of mothers is consistent with other published data ${ }^{1011}$ on the impact of early child death on mothers' risk of mortality. However, this study includes a group of children with broader age and range of lifelimiting diagnoses. ${ }^{11}$ The higher incidence rates of CVD, type 2 diabetes and hypertension in the current study are important risk factors for morbidity and mortality, but these may be amenable to primary or secondary preventative strategies.

While these findings highlight higher incidence rates of physical and mental health conditions, it cannot identify how these mothers could be better supported. Some research supports the use of peer support services to maintain the health and wellbeing in parents of children with disabilities, ${ }^{39}$ but to date, none have accounted for the additional pressure of being told that your child may die. ${ }^{40}$

These mothers will have many more contacts with paediatric healthcare providers than with their own healthcare provider, and there may be a role of paediatric providers in providing support or signposting to appropriate services. Family centred care is an approach that has highlighted the importance of the 
Table 4 Multivariable models for maternal physical health outcomes

\begin{tabular}{|c|c|c|c|c|c|c|c|c|c|c|}
\hline & Obesity & $\mathrm{n}=32675$ & $\begin{array}{l}\text { Cardiovascular } \\
\text { disease }\end{array}$ & $\mathrm{n}=35122$ & Hypertension & $n=33904$ & $\begin{array}{l}\text { Type } 2 \\
\text { diabetes }\end{array}$ & $\mathrm{n}=34869$ & $\begin{array}{l}\text { Back } \\
\text { pain }\end{array}$ & $\mathrm{n}=23111$ \\
\hline & IRR & $95 \% \mathrm{Cl}$ & IRR & $95 \% \mathrm{Cl}$ & IRR & $95 \% \mathrm{Cl}$ & IRR & $95 \% \mathrm{Cl}$ & IRR & $95 \% \mathrm{Cl}$ \\
\hline Child has no long-term condition & REF & & REF & & REF & & REF & & REF & \\
\hline Child has a life-limiting condition & 1.32 & 1.20 to 1.45 & 1.73 & 1.27 to 2.36 & 1.35 & 1.20 to 1.52 & 1.22 & 1.01 to 1.48 & 1.08 & 1.01 to 1.15 \\
\hline Child has a chronic condition & 1.12 & 1.03 to 1.23 & 1.06 & 0.76 to 1.49 & 1.21 & 1.08 to 1.36 & 1.09 & 0.90 to 1.32 & 1.16 & 1.09 to 1.23 \\
\hline Mothers' age & 0.98 & 0.97 to 0.99 & 1.12 & 1.09 to 1.14 & 1.07 & 1.06 to 1.08 & 1.07 & 1.05 to 1.08 & 0.99 & 0.99 to 0.99 \\
\hline \multicolumn{11}{|l|}{ Deprivation category } \\
\hline 1 (least deprived) & REF & & REF & & REF & & REF & & REF & \\
\hline 2 & 1.67 & 1.44 to 1.92 & 1.32 & 0.80 to 2.19 & 1.09 & 0.93 to 1.27 & 1.02 & 0.76 to 1.37 & 1.11 & 1.02 to 1.20 \\
\hline 3 & 1.89 & 1.64 to 2.18 & 2.06 & 1.29 to 3.30 & 1.38 & 1.18 to 1.61 & 1.67 & 1.27 to 2.18 & 1.15 & 1.06 to 1.25 \\
\hline 4 & 2.27 & 1.97 to 2.61 & 3.25 & 2.08 to 5.07 & 1.66 & 1.43 to 1.93 & 2.06 & 1.59 to 2.67 & 1.22 & 1.12 to 1.32 \\
\hline 5 (most deprived) & 2.62 & 2.27 to 3.03 & 3.54 & 2.21 to 5.67 & 1.69 & 1.44 to 1.99 & 2.51 & 1.92 to 3.29 & 1.30 & 1.19 to 1.42 \\
\hline \multicolumn{11}{|l|}{ Ethnic group } \\
\hline White & REF & & REF & & REF & & REF & & REF & \\
\hline South Asian & 1.08 & 0.92 to 1.26 & 1.40 & 0.83 to 2.36 & 1.47 & 1.19 to 1.79 & 3.32 & 2.62 to 4.20 & 1.28 & 1.15 to 1.42 \\
\hline Black & 1.28 & 1.05 to 1.57 & 0.94 & 0.42 to 2.08 & 2.50 & 2.00 to 3.13 & 1.65 & 1.11 to 2.45 & 1.26 & 1.10 to 1.45 \\
\hline Chinese & 0.10 & 0.01 to 0.70 & 0.00 & 0.00 & 1.27 & 0.60 to 2.68 & 0.55 & 0.08 to 3.95 & 0.62 & 0.38 to 1.00 \\
\hline Mixed & 0.79 & 0.49 to 1.25 & 0.00 & 0.00 & 1.70 & 1.05 to 2.75 & 0.84 & 0.27 to 2.61 & 1.11 & 0.85 to 1.44 \\
\hline Other & 0.77 & 0.54 to 1.09 & 1.38 & 0.51 to 3.79 & 1.10 & 0.73 to 1.66 & 1.44 & 0.79 to 2.64 & 1.08 & 0.88 to 1.32 \\
\hline Missing & 0.53 & 0.42 to 0.68 & 0.18 & 0.07 to 0.50 & 0.89 & 0.73 to 1.08 & 0.53 & 0.35 to 0.81 & 0.75 & 0.66 to 0.85 \\
\hline Number of GP consultations & 1.01 & 1.01 to 1.01 & 1.01 & 1.01 to 1.01 & 1.01 & 1.01 to 1.01 & 1.01 & 1.01 to 1.01 & 1.01 & 1.01 to 1.01 \\
\hline Smoking & & & 1.26 & 0.95 to 1.67 & 1.12 & 1.01 to 1.23 & & & & \\
\hline \multicolumn{11}{|l|}{ Region } \\
\hline North East & 1.21 & 0.93 to 1.57 & 1.46 & 0.53 to 4.07 & 1.21 & 0.85 to 1.73 & 1.30 & 0.78 to 2.19 & 1.11 & 0.93 to 1.34 \\
\hline North West & 1.03 & 0.88 to 1.19 & 1.12 & 0.30 to 4.18 & 1.25 & 1.04 to 1.51 & 1.12 & 0.84 to 1.51 & 1.10 & 1.00 to 1.21 \\
\hline Yorkshire and Humber & 0.98 & 0.74 to 1.29 & 2.92 & 0.88 to 9.76 & 1.10 & 0.78 to 1.54 & 1.79 & 1.13 to 2.85 & 1.00 & 0.84 to 1.19 \\
\hline East Midlands & 2.31 & 1.82 to 2.93 & 1.16 & 0.40 to 3.33 & 2.05 & 1.49 to 2.83 & 2.39 & 1.46 to 3.93 & 1.36 & 1.12 to 1.66 \\
\hline West Midlands & 1.28 & 1.09 to 1.49 & 1.94 & 0.68 to 5.49 & 1.16 & 0.95 to 1.41 & 1.03 & 0.75 to 1.41 & 1.01 & 0.91 to 1.13 \\
\hline East of England & 1.07 & 0.91 to 1.27 & 1.12 & 0.39 to 3.22 & 1.38 & 1.14 to 1.67 & 1.09 & 0.79 to 1.50 & 1.08 & 0.98 to 1.20 \\
\hline South West & 1.24 & 1.06 to 1.44 & 1.12 & 0.38 to 3.32 & 1.02 & 0.83 to 1.25 & 1.07 & 0.77 to 1.47 & 0.96 & 0.87 to 1.07 \\
\hline South Central & 1.06 & 0.89 to 1.25 & 0.92 & 0.31 to 2.70 & 1.15 & 0.94 to 1.41 & 1.08 & 0.78 to 1.50 & 1.06 & 0.96 to 1.17 \\
\hline London & REF & & & & & & & & & \\
\hline South East Coast & 0.87 & 0.74 to 1.03 & 1.29 & 0.44 to 3.79 & 1.23 & 1.01 to 1.50 & 0.89 & 0.62 to 1.26 & 0.98 & 0.89 to 1.08 \\
\hline \multicolumn{11}{|l|}{ Child sex } \\
\hline \multicolumn{11}{|l|}{ Male } \\
\hline Female & 1.01 & 0.94 to 1.09 & 0.88 & 0.68 to 1.16 & 0.96 & 0.87 to 1.06 & 0.88 & 0.75 to 1.04 & 0.91 & 0.86 to 0.96 \\
\hline Baby birth year & 1.01 & 1.00 to 1.02 & 1.00 & 0.98 to 1.03 & 0.99 & 0.97 to 1.00 & 0.99 & 0.98 to 1.01 & 1.01 & 1.00 to 1.02 \\
\hline
\end{tabular}

GP, general practitioner; IRR, incidence rate ratio; REF, reference.

family unit when providing health services to children with chronic conditions or disabilities, ${ }^{41}$ but the implementation of this model of care has been limited. ${ }^{42}$ Further research should focus on the most feasible ways to support health needs of this population of mothers.

\section{Strengths and weaknesses of the study}

This was a longitudinal study which used a nationally representative sample of primary and secondary healthcare data. ${ }^{14}$ This allowed the comprehensive identification of the child's disease status and maternal outcomes of interest. Causality cannot be fully established using an observational study design, but we have demonstrated the temporality of the relationship between exposure and outcome and a dose-response relationship with key health outcomes using as robust a study design as possible.

This study is reliant on the quality of diagnostic coding within the datasets. It is difficult to assess severity or prognoses due to heterogeneity of some conditions and variation in coding practice among GPs. We have no evidence that these coding practices would differ between the groups of mothers. Although we used data on age and smoking, we were missing information on some key confounders, including family history of CVD, nutrition and alcohol intake. Causes of death data were not available.

This study focused on mothers due to the mothers usually, but not exclusively, being the main carers for these children. ${ }^{5}$ It is also not currently possible reliably to identify father-child dyads within the CPRD data.

\section{CONCLUSION}

This study clearly demonstrates the higher incidence rates of physical and mental health in mothers of children with a lifelimiting condition. Further research is required to understand how best to support these mothers, but healthcare providers should consider how they could provide preventative and treatment services for this population.

\section{Twitter Lorna K Fraser @|ornafraser10}

Contributors LKF had the original idea for this study, carried out the analyses and wrote the first draft of this manuscript. FEMM, JA, SG, TS and CH contributed to the development of this idea and the study design and revised the manuscript. 
Funding This paper is independent research arising from a Career Development Fellowship held by Lorna Fraser (CDF-2018-11-ST2-002) supported by the National Institute for Health Research.

Disclaimer The views expressed in this publication are those of the author(s) and not necessarily those of the NHS, the National Institute for Health Research or the Department of Health.

Competing interests None declared.

Patient consent for publication Not required.

Ethics approval This study protocol has approval from the Independent Scientific Advisory Committee for the UK Medicines and Healthcare products Regulatory Agency Database Research (protocol 18_313).

Provenance and peer review Not commissioned; externally peer reviewed.

Data availability statement Data may be obtained from a third party and are not publicly available. the clinical codes used for this study are provided as supplementary material. The patient level data cannot be shared but can be accessed via the Clinical Practice Research Datalink.

Supplemental material This content has been supplied by the author(s). It has not been vetted by BMJ Publishing Group Limited (BMJ) and may not have been peer-reviewed. Any opinions or recommendations discussed are solely those of the author(s) and are not endorsed by BMJ. BMJ disclaims all liability and responsibility arising from any reliance placed on the content. Where the content includes any translated material, BMJ does not warrant the accuracy and reliability of the translations (including but not limited to local regulations, clinical guidelines, terminology, drug names and drug dosages), and is not responsible for any error and/or omissions arising from translation and adaptation or otherwise.

Open access This is an open access article distributed in accordance with the Creative Commons Attribution 4.0 Unported (CC BY 4.0) license, which permits others to copy, redistribute, remix, transform and build upon this work for any purpose, provided the original work is properly cited, a link to the licence is given, and indication of whether changes were made. See: https://creativecommons.org/ licenses/by/4.0/.

\section{ORCID iD}

Lorna K Fraser http://orcid.org/0000-0002-1360-4191

\section{REFERENCES}

1 Fraser LK, Gibson-Smith D, Jarvis S. 'Make Every Child Count' Estimating current and future prevalence of children and young people with life-limiting conditions in the United Kingdom York, UK: University of York, 2020.

2 TfS L. A Guide to Children's Palliative Care. Bristol, 2018.

3 Fraser LK, Parslow R. Children with life-limiting conditions in paediatric intensive care units: a national cohort, data linkage study. Arch Dis Child 2018;103:540-7.

4 National Confidential Enquiry into Patient Outcome and Death. Balancing the pressures: a review of the quality of care provided to children and young people aged $0-24$ years who were receiving long-term ventilation. London: National Confidential Enquiry into Patient Outcome and Death, 2020.

5 Stabile M, Allin S. The economic costs of childhood disability. Future Child 2012;22:65-96.

6 National Institute for Health and Crae Excellence (NICE). End of life care for infants, children and young people with life-limiting conditions: planning and management, 2016

7 Thurston S, Paul L, Loney P, et al. Associations and costs of parental symptoms of psychiatric distress in a multi-diagnosis group of children with special needs. Intellect Disabil Res 2011;55:263-80.

8 Brehaut JC, Kohen DE, Raina P, et al. The health of primary caregivers of children with cerebral palsy: how does it compare with that of other Canadian caregivers? Pediatrics 2004;114:e182-91

9 Lach LM, Kohen DE, Garner RE, et al. The health and psychosocial functioning of caregivers of children with neurodevelopmental disorders. Disabil Rehabil 2009:31:607-18.

10 Harper M, O'Connor RC, O'Carroll RE. Increased mortality in parents bereaved in the first year of their child's life. BMJ Support Palliat Care 2011:1:306-9.

11 Cohen E, Horváth-Puhó E, Ray JG, et al. Association between the birth of an infant with major congenital anomalies and subsequent risk of mortality in their mothers. JAMA 2016;316:2515-24.

12 Lee MH, Park C, Matthews AK, et al. Differences in physical health, and health behaviors between family caregivers of children with and without disabilities. Disabil Health J 2017;10:565-70.
13 Benchimol El, Smeeth L, Guttmann A, et al. The reporting of studies conducted using observational Routinely-collected health data (record) statement. PLoS Med 2015;12:e1001885.

14 Herrett E, Gallagher AM, Bhaskaran K, et al. Data resource profile: clinical practice research Datalink (CPRD). Int J Epidemiol 2015;44:827-36.

15 Clinical Practice Research Datalink. Hospital Episode Statistics (HES) Admitted Patient Care and GOLD Documentation (Set 14). Medicines \& Healthcare products Regulatory Agency, 2017.

16 Health \& Social Care Information Centre. Methodology for creation of the Hes patient ID (HESID), 2014

17 Herbert A, Wijlaars L, Zylbersztejn A, et al. Data resource profile: Hospital episode statistics admitted patient care (Hes APC). Int J Epidemiol 2017;46:1093-1093i.

18 NHS Digital. Mental health services data set. NHS digital, 2020.

19 Fraser LK, Miller M, Hain R, et al. Rising national prevalence of life-limiting conditions in children in England. Pediatrics 2012;129:e923-9.

20 Jarvis S, Parslow RC, Hewitt C, et al. Gps' role in caring for children and young people with life-limiting conditions: a retrospective cohort study. Br J Gen Pract 2020;70:e221-9

21 Hardelid P, Dattani N, Gilbert R, et al. Estimating the prevalence of chronic conditions in children who die in England, Scotland and Wales: a data linkage cohort study. BMJ Open 2014;4:e005331.

22 Zhu Y, Edwards D, Payne RA, et al. Characteristics, service use, and mortality of clusters of multimorbid patients in England: a population-based study. The Lancet 2019;394:S102.

23 Wilson CL, Rhodes KM, Payne RA. Financial incentives improve recognition but not treatment of cardiovascular risk factors in severe mental illness. PLoS One 2017;12:e0179392-e.

24 Doran T, Kontopantelis E, Valderas JM, et al. Effect of financial incentives on incentivised and non-incentivised clinical activities: longitudinal analysis of data from the UK quality and outcomes framework. BMJ 2011;342:d3590.

25 Reeves D, Springate DA, Ashcroft DM, et al. Can analyses of electronic patient records be independently and externally validated? the effect of statins on the mortality of patients with ischaemic heart disease: a cohort study with nested case-control analysis. BMJ Open 2014;4:e004952.

26 Kontopantelis E, Springate DA, Reeves D, et al. Glucose, blood pressure and cholesterol levels and their relationships to clinical outcomes in type 2 diabetes: a retrospective cohort study. Diabetologia 2015:58:505-18.

27 Government DfCaL. The English indices of deprivation 2015, 2015.

28 (NICE). NIfHaCE. Coronavirus (COVID-19): rapid quidelines and evidence summaries. UK: NICE, 2020.

29 StataCorp. Stata statistical software: release 14. College Station, TX: StataCorp LP 2017.

30 Barlow JH, Cullen-Powell LA, Cheshire A. Psychological well-being among mothers of children with cerebral palsy. Early Child Dev Care 2006:176:421-8.

31 Emerson E. Mothers of children and adolescents with intellectual disability: social and economic situation, mental health status, and the self-assessed social and psychological impact of the child's difficulties. J Intellect Disabil Res 2003;47:385-99.

32 Gallagher S, Phillips AC, Oliver C, et al. Predictors of psychological morbidity in parents of children with intellectual disabilities. J Pediatr Psychol 2008;33:1129-36.

33 Singer GHS. Meta-Analysis of comparative studies of depression in mothers of children with and without developmental disabilities. Am J Ment Retard 2006:111:155-69.

34 Masefield SC, Prady SL, Sheldon TA, et al. The caregiver health effects of caring for young children with developmental disabilities: a meta-analysis. Matern Child Health $J$ 2020;24:561-74

35 Tong HC, Haig AJ, Nelson VS, et al. Low back pain in adult female caregivers of children with physical disabilities. Arch Pediatr Adolesc Med 2003:157:1128-33.

36 Cohn LN, Pechlivanoglou P, Lee Y, et al. Health outcomes of parents of children with chronic illness: a systematic review and meta-analysis. J Pediatr 2020;218:e2:166-77.

37 Fraser LK, Jarvis SW, Moran N, et al. Children in Scotland requiring palliative care: identifying numbers and needs (the ChiSP study. York, UK: University of York, 2015.

38 Collins A, Burchell J, Remedios C, et al. Describing the psychosocial profile and unmet support needs of parents caring for a child with a life-limiting condition: a crosssectional study of caregiver-reported outcomes. Palliat Med 2020;34:358-66.

39 Shilling V, Morris C, Thompson-Coon J, et al. Peer support for parents of children with chronic disabling conditions: a systematic review of quantitative and qualitative studies. Dev Med Child Neurol 2013;55:602-9.

40 Borek AJ, McDonald B, Fredlund M, et al. Healthy parent carers programme: development and feasibility of a novel group-based health-promotion intervention. BMC Public Health 2018;18:270.

41 Moore MH, Mah JK, Trute B. Family-centred care and health-related quality of life of patients in paediatric neurosciences. Child Care Health Dev 2009:35:454-61.

42 Franck LS, Callery P. Re-thinking family-centred care across the continuum of children's healthcare. Child Care Health Dev 2004;30:265-77. 